\title{
MANDA QUEM PODE, OBEDECE QUEM TEM JUÍZO: REFLEXÕES EM BUSCA DO EQUILÍBRIO ENTRE AUTORIDADE E AUTORIA EM SERVIÇOS DE DESIGN
}

\author{
Melissa Merino Lesnovski \\ Universidade do Vale do Rio dos Sinos \\ melissa.lesnovski@gmail.com \\ Filipe Campelo Xavier da Costa \\ Universidade do Vale do Rio dos Sinos \\ fcampelo@unisinos.br
}

Resumo: As relações entre clientes e consultorias de design são, frequentemente, marcadas por conflitos originários de um sistema de pressões e cessões entre todos os atores do processo. Ao se procurar compreender a dinâmica entre essas organizações, representada pelas pessoas que as compõem, é possível visualizar dois eixos relacionais: autoridade-subserviência e mecenato-autoria. Ambos os eixos, ao terem seus elementos de poder combinados, geram um binário de autoridade e autoria, polos de poder que regulariam a dinâmica entre cliente e consultoria de design. Este artigo se lança à exploração de referenciais teóricos para uma análise do tema através das lentes do design estratégico, em busca de modelos que colaborem para a reflexão e melhoria dessas relações. O percurso realizado apontou para a emergência de três eixos de discussão: o designer como facilitador, provocador e integrador; a relação cliente-fornecedor como coletivos que projetam e o design discourse e as redes de projeto. Os achados apontam a existência de elementos consistentes para tanto uma discussão sobre as relações de trabalho nos vários domínios do design quanto o fomento a uma visão mais consciente das limitações e cristalização de posições dos papéis corporativos dos atores envolvidos no processo.

Palavras-chave: gestão do design, design estratégico, conflito de interesses, consultoria de design, serviços de design

Abstract: Relationships between design consultants and their clients are,
more often than not, prone to conflicts and anxiety derived from a system
of pressures and cessions among the several actors of the process. In order
to understand the dynamics among these organizations and the people
invested in them, two relational axis are proposed: authority-subservience
and patronage-authorship. Both axis, when combined, generate a binary
involving authority and authorship, power poles that regulate the dynamics
between client and consultant organizations. This paper explores
theoretical references in order to analyze the aforementioned theme
through the lenses of strategic design, searching for models that may 
collaborate in the reflection and improvement of these relationships. The exploratory path pointed to the emergency of three discussion topics: the designer as a facilitator, provoker and integrator; design-client relationship as collectives that design and the design discourse and design networks. Findings point to the existence of consistent elements that may bring relevance to the discussion of either the work relationships on the several domains of design, the consequences of mindset limitations and the opportunities that may be harnessed through collaboration, openness and networked structuring.

Keywords: design management, strategic design, conflict of interests, design consultancy, design services

\section{INTRODUÇÃO}

No cenário competitivo contemporâneo, notadamente complexo, as organizações se vêem, por um lado, pressionadas a proverem ofertas inovadoras que as diferenciem de seus concorrentes e, por outro, a otimizarem seus custos por um viés orientado à eficiência operacional. Em meio a essa realidade, a contratação de serviços de design por meio de consultorias emerge como um formato que possibilita aliar inovação à flexibilidade de custos (JEVNAKER, BRUCE, 1998).

As relações entre clientes e suas consultorias de design, formalmente, se baseiam em uma prestação de serviços entre empresas, orientada à produção de artefatos, serviços ou estratégias (BAGDONAITE, 2015). Os serviços são levados a cabo através da interação entre atores presentes nas empresas cliente e fornecedora e, eventualmente, em outras organizações envolvidas nos projetos em curso.

Essas interações revelam-se um sistema de pressões, cessões e atritos entre atores tanto da organização cliente quanto da consultoria. A efemeridade dos contratos e a baixa previsibilidade do produto final, por serem frutos da relação entre indivíduos e não de uma fórmula infalível, levantam a suspeita que deu origem a esta investigação - de que o sucesso de um empreendimento entre cliente e consultoria de design poderia estar mais vinculado à dinâmica entre os atores do que às suas respectivas capacidades técnicas.

A partir das referências teóricas percorridas neste trabalho, acompanhou-se a emergência de dois eixos relacionais sobre os quais a presente reflexão é tecida. 0 primeiro é a relação autoridade-subserviência, marcada pelo poder de sugestão, aprovação, veto e provimento de recursos por parte do cliente, onde este aflora como o "dono" do processo e mandante das relações, enquanto a consultoria desempenha um papel subserviente. $O$ segundo eixo é a relação mecenato-autoria, onde a autoria é exclusividade da consultoria, concentradora tanto dos louros quanto da responsabilidade sobre o sucesso do produto final, enquanto o mecenato representa o papel de provedor do cliente.

Em virtude da instabilidade desse modelo polarizado, pergunta-se: não poderia essa relação ser redesenhada para uma melhor distribuição de tensões e contribuições, permitindo maior colaboração entre os atores? Que tipo de alternativa ao binário de poder autoridade-autoria poderia emergir a partir dos referenciais do 
design estratégico, e quais mudanças de paradigmas ela acarretaria dentro do processo projetual?

Este artigo busca investigar as possíveis contribuições do design estratégico para a reflexão sobre o relacionamento cliente-consultoria do design através de autores que abordam a gestão do design, design para serviços e design estratégico.

As reflexões tecidas na discussão exploram o papel do designer, representante da consultoria de design, como facilitador, provocador e integrador; a integração entre designer e cliente como coletivos que projetam; e o design discourse e as redes de projeto. As considerações finais tensionam os eixos construídos na discussão, cogitando possíveis condições e implicações da mudança cultural necessária na relação entre a consultoria de design e o cliente.

\section{REFERENCIAL TEÓRICO}

\subsection{A consultoria de design}

Para este artigo, convencionou-se chamar "consultoria de design" às organizações que prestam serviços dentro do campo do design a outras organizações em áreas como arquitetura, design gráfico, design de produtos, publicidade e comunicação digital, dentre outras. Seu formato de trabalho pode variar de acordo com a área específica de atuação e posicionamento estratégico: contratação por projeto, fee, royalties sobre os produtos desenvolvidos ou diversas combinações dessas modalidades (MOZOTA et al,, 2011).

A análise sobre o contexto de fundação de uma empresa de design é relevante para este estudo ao apresentar as motivações e modelo mental influentes na estruturação do negócio. As empresas de design são fundadas por designers e, nessa condição, são influenciadas pelas experiências, filosofia e estratégias de negócio de seus fundadores, sendo sua personalidade e inclinação profissional fatores preponderantes no posicionamento e área de atuação da empresa (MOZOTA et al., 2011).

Se a empresa de design é modelada pela forma de pensar do designer, torna-se interessante investigar a visão do designer sobre seu próprio negócio. Meyer (2010) reflete sobre as dificuldades dos designers em se fazerem respeitar por seus clientes: ao mesmo tempo em que reclamam do baixo conhecimento do público sobre suas atividades, parecem fomentar uma aura de mistério ao redor de si mesmos.

A fascinação com a criatividade - ou com a ideia que se tem da criatividade pode explicar um dos principais fatores de diferenciação de empresas de design no mercado: as premiações de design. A partir de seu peso na escolha por parte do público comprador, as premiações são reconhecidas como capital da empresa de design na conquista de clientes, além de proverem reconhecimento dentro do próprio círculo profissional (MEYER, 2010; MOZOTA et al., 2011). A impermeabilidade dos critérios de julgamento ao público leigo, contudo, contribui para a diminuição de sua credibilidade frente a clientes preocupados com a adequação do projeto ao mercado e a seus objetivos de negócio (LEAKE, 2014).

Ao contrário de outros negócios consultivos, como a medicina e a advocacia, no design a autoridade está deslocada para o cliente, muitas vezes de forma absoluta e imperativa. Apesar de o designer ser o especialista, é notável a influência que a opinião do cliente possui na relação (MEYER, 2010). A atitude autoritária do cliente na relação 
com a empresa de design gera atritos no relacionamento e ressentimento por parte dos profissionais do design, desautorizados da exclusividade sobre o pensar design. Bruce e Morris (1994) levantam evidências de que a postura passiva de designers seria, em alguns casos, provocada por eles próprios, por receio de que o envolvimento mais profundo ampliasse sua atuação sem que o cliente concordasse com uma revisão de seus honorários.

Se a questão for analisada pela visão de Lockwood (2010), a exclusividade do designer sobre o pensar design não existiria de fato: o design estaria em todo o lugar e tudo o que é feito por seres humanos seria design - portanto, todos seriam designers em potencial. Por esse ponto de vista, haveria uma ruptura da atividade do designer como guardião do conhecimento. O designer clássico compartilharia espaço com um designer-mediador, orientador e habilitador do design praticado por não-designers.

\subsection{A empresa cliente}

Neste artigo, são chamadas de "clientes" as organizações que contratam serviços de consultorias de design. Essa contratação de serviços abrange tanto consultorias técnicas quanto estratégicas e pode ocorrer em diferentes formatos, alinhados às diretrizes estratégicas da empresa contratante: designers empregados, consultorias de design externas ou uma combinação entre as duas modalidades (BRUCE, MORRIS, 1994; MOZOTA et al., 2011).

As empresas contratantes optam por consultorias externas de design por diversas razões, dentre as quais limitações financeiras e motivos estratégicos. Segundo Mozota et al. (2011), a terceirização do design está relacionada à busca de vantagem competitiva - a consecução dos objetivos estratégicos, portanto, é influenciadora da própria visão dos atores dessa organização, orientados a metas definidas. A vantagem competitiva relacionada à terceirização dos serviços de design também se deve à efemeridade do formato de contratação: segundo Best (2012), tem-se acesso a níveis mais profundos de conhecimento sem compromisso com a manutenção da relação após o término do projeto. Bruce e Doucherty (1993) ponderam que a perenidade dos contratos está diretamente relacionada com a visão estratégica e expectativa que o cliente possui sobre o tipo de projeto a ser realizado, desde projetos longos que promovem grande familiaridade do designer com a organização cliente até contratações isoladas, com baixo custo de adesão e descarte.

Embora aparentemente o modelo mental dos atores da empresa cliente seja orientado a metas, Best (2012) pondera que a qualidade e a natureza das relações interpessoais têm grande impacto no sucesso dos projetos da organização. Enquanto se é esperado da consultoria de design que proveja a solução para o problema apresentado, cabe ao cliente a comunicação da visão ou direção estratégica da organização, tanto para seu corpo de funcionários quanto para consultores externos (BEST, 2012). Algumas das barreiras à relação entre cliente e consultoria de design estão diretamente relacionadas à permeabilidade da organização cliente em relação a atores externos: a hostilidade das equipes do cliente em relação ao fornecimento de informação estratégica à consultoria de design e ao reconhecimento pela autoria do projeto são ameaças à colaboração continuada entre as organizações (LEONARDBARTON, 1995; JEVNAKER, BRUCE, 1998). A rigidez e aversão a riscos nas organizações, combinada à falta de entendimento sobre o design, pode levar clientes a enxergarem o 
design como uma ameaça a suas carreiras, com poucos benefícios tangíveis (WATT et al., 2000).

Pode-se expandir essa responsabilidade da organização cliente por meio da análise das contribuições de Verganti (2012) e Manzini (2010) ao proporem o papel da organização como participante ativa da conversação com o design discourse (VERGANTI, 2012) e articuladora de plataformas habilitantes de colaboração (MANZINI, 2010). As proposições de ambos, assim como contribuições presentes nas próximas páginas deste artigo, insinuam que o processo de design pode ganhar com o decréscimo da polarização das posições e, como consequência, com o aumento da colaboração entre os atores.

\subsection{Cliente e fornecedor: entre a autoridade e a autoria}

A relação entre consultorias de design e seus respectivos clientes é, usualmente, marcada pela sensação de estranhamento e desconfiança (LEONARDBARTON, 1995; JEVNAKER, BRUCE, 1998; WATT et al., 2000; SILVA E TARSITANO, 2006; MEYER, 2010). Os riscos dessa instabilidade atingem ambos os atores: para a empresa de design, a ruptura ou descumprimento do contrato significaria perda financeira. Para o cliente, significaria o início de um novo e longo processo de aprendizado com outro fornecedor. Se ambos os atores sofrem prejuízos com o enfraquecimento da relação, seriam seus interesses irreconciliáveis? Primeiramente, este artigo se propõe a examinar a origem das diferenças e conflitos entre eles.

À primeira vista, poder-se-ia supor que as diferenças entre cliente e empresa de design seriam originárias da formação de seus integrantes, notadamente os que realizam as interfaces entre as duas empresas (profissionais de atendimento ou gerentes de projeto, por parte do fornecedor, e gerentes ou analistas, por parte do cliente). Questiona-se, contudo, se as diferenças de expectativas, modelos mentais e postura não possam derivar mais dos papéis organizacionais que representam do que de características inerentes a suas formações.

Silva e Tarsitano (2006) relacionam o papel dos profissionais de interface entre as empresas como gatekeepers (guardiões, em tradução livre) das informações de ambos os lados. Essa condição traria uma vantagem de relacionamento, caso houvesse afinidade entre os profissionais, mas também localizaria essa afinidade apenas em ambos os atores, sem envolver os demais stakeholders nas organizações cliente e fornecedor. Nessa visão, o relacionamento entre duas organizações seria aprisionado à fluência da relação entre duas pessoas, o que traria riscos ao processo.

A partir da análise das evidências de qualidade percebida do produto final em relação ao relacionamento entre os atores das organizações, encontram-se subsídios que apontam para a relevância dos laços interpessoais: a agência de publicidade RPA e o jornal USA Today empreenderam uma pesquisa com 143 profissionais de nível senior em agências de publicidade e departamentos de marketing de organizações, no projeto denominado The Naked Truth. Nela, mais de $80 \%$ das agências e clientes vinculam a qualidade do resultado final aos relacionamentos duradouros e à colaboração do início ao fim do projeto. A quase totalidade dos respondentes (98\%), afirmou que a confiança leva à boa qualidade (LEAKE, 2014), havendo indícios, em suas falas, de que a falta de confiança existente entre contratantes e fornecedores residiria na diferença de percepções e modelos mentais. As falas dos clientes reprovam a preocupação excessiva das agências com prêmios e um certo deslumbramento com 
suas próprias criações, ao passo que as agências criticam a falta de transparência e engajamento dos clientes nos projetos (LEAKE, 2014). Esses dados se alinham com os achados de Bruce e Docherty (1993) sobre os fatores que conduzem a relações de longo prazo entre clientes e consultorias de design: rápida disponibilidade das soluções, empatia entre as partes envolvidas, confiança, respeito e entendimento profundo entre o cliente e o designer.

A partir da leitura dos autores consultados e da consequente reflexão sobre a prática profissional, elaborou-se um quadro comparativo (Quadro 1) das visões e posições relativas de cliente e consultoria do design em relação a parâmetros relevantes em seu relacionamento: poder de barganha, modelo mental, reconhecimento profissional, relação com a criação e relação de poder. Nesse quadro, identificou-se dois eixos relacionais que parecem estruturar poder e influência dentro da relação cliente-consultoria: autoridade-subserviência e mecenato-autoria.

Quadro 1 - Posições Relativas de Cliente e Consultoria

\begin{tabular}{|l|l|l|}
\hline & CLIENTE & CONSULTORIA \\
\hline Poder de Barganha & Alto & Baixo \\
\hline Modelo mental & Gestão & Design \\
\hline Reconhecimento profissional & Objetivos de negócio & Prêmios \\
\hline Relação com a criação & Mecenato & Autoria \\
\hline Relação de poder & Autoridade & Subserviência \\
\hline
\end{tabular}

Fonte: Quadro elaborado pelos autores, com base em reflexões sobre a pesquisa realizada.

\subsection{Autoridade-Subserviência e Mecenato-Autoria}

Como citado por Meyer (2010), a autoridade exercida pelo cliente dentro do processo de design supera as referências encontradas em outros negócios. A autoridade é diretamente derivada do poder econômico da empresa contratante, sendo a empresa de design normalmente submissa para resguardar sua sustentabilidade financeira (Figura 1).

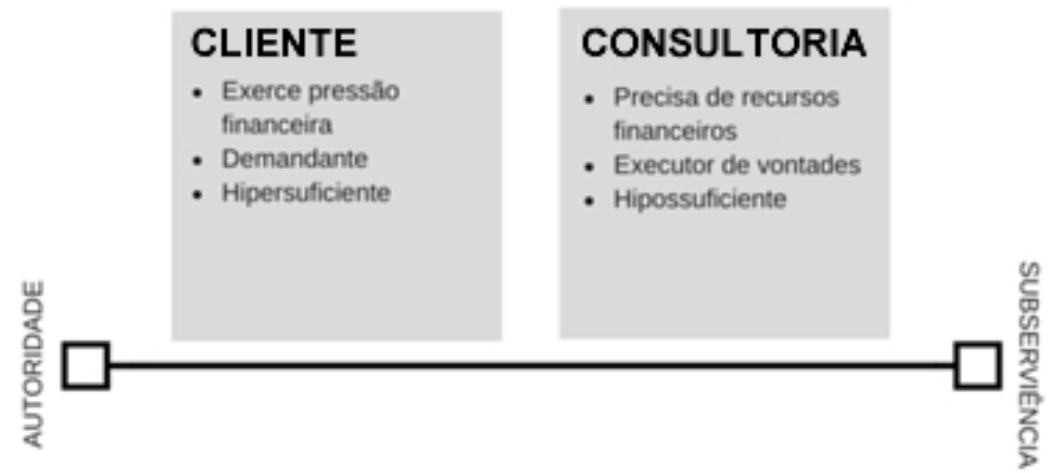

Figura 1 - Eixo Autoridade-Subserviência.

Fonte: elaborada pelos autores, com base em reflexões sobre a pesquisa realizada.

Possivelmente devido ao pouco conhecimento público sobre a atividade do design, além da dificuldade de mensuração de seu resultado, o designer é recebido com desconfiança e ansiedade pelo cliente, resultando em posturas autoritárias ou controladoras por parte deste, visando o melhor retorno sobre o investimento (WATT 
et al. 2000; LEAKE, 2014). Ao tentar controlar a atividade, o cliente por vezes culmina por tornar o consultor de design um executor subserviente de seus desígnios (BRUCE, MORRIS, 1994), porém com responsabilidade final sobre o produto do trabalho.

Se o poder da autoridade está relacionado à empresa contratante, os méritos pela autoria são, comumente, atribuídos à consultoria de design (LEAKE, 2014). Podese enxergar na autoria uma certa investidura de poder, convertida em vantagem competitiva para captação de novos clientes ou para construção de reputação no meio profissional. As premiações de design auxiliam a construção desse capital de autoria ao valorizar a atuação do designer, tanto pela qualidade percebida e avalizada de um projeto quanto por sua trajetória profissional.

Ao cliente, é relegado o papel de mecenas - aquele que supre recursos para que a criação ocorra, não estando envolvido dentro do processo criativo, nem sendo citado com mérito nas premiações. Assim como na relação autoridade-subserviência, nota-se um desequilíbrio de poder na relação de mecenato-autoria (figura 2), também gerador de ansiedade, desconfiança e atrito na relação cliente-consultoria.

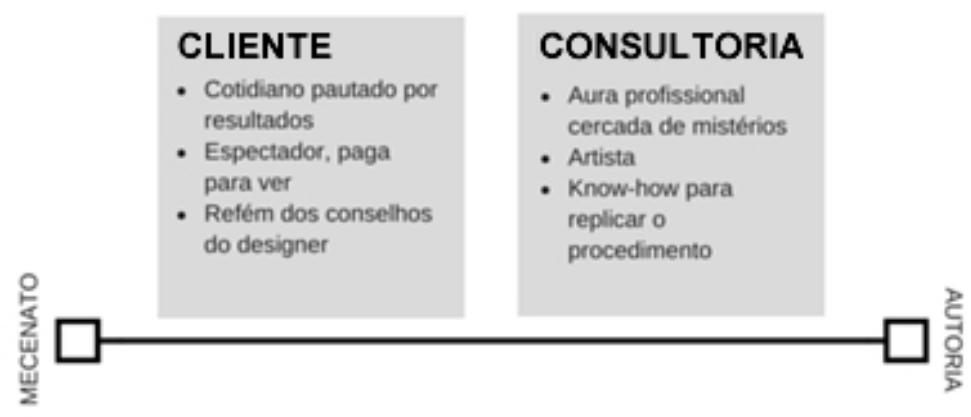

Figura 2 - Eixo Mecenato-Autoria.

Fonte: elaborada pelos autores, com base em reflexões sobre a pesquisa realizada.

\subsection{Pólos de poder: Autoridade e autoria}

A partir da síntese dos dois eixos acima apresentados em um só modelo (Figura 3), pode-se identificar dois polos de poder: a autoridade e a autoria, respectivamente atribuídas às empresas clientes e às consultorias de design.



Figura 3 - Eixos Autoridade-Subserviência e Mecenato-Autoria.

Fonte: elaborada pelos autores, com base em reflexões sobre a pesquisa realizada. 
Pode-se observar, a partir das referências de Bruce e Docherty (1994), LeonardBarton (1995), Meyer (2010), Mozota et al. (2011) e Leake (2014), que ambos os polos são intimamente conectados à consciência de papel de cada ator e representam pontos de desequilíbrio na relação. Além dos polos de poder, pode-se observar na Figura 3 os polos de entrega (mecenato-subserviência), que representariam as cessões, devidas ou não, inerentes ao modelo.

Futuras investigações poderão aprofundar, validar ou questionar esse modelo hipotético com dados de campo, situando relações dentro dos eixos.

\subsection{Articulando polos: em busca de modelos colaborativos}

Dentro do contexto polarizado e instável entre a autoridade e a autoria, buscou-se referenciais teóricos para refletir se um modelo híbrido, colaborativo, não seria capaz de distribuir de melhor forma as tensões, responsabilidades e créditos pelo trabalho desenvolvido (BRUCE, MORRIS, 1994). Tal tipo de modelo, marcado pela transparência e por uma visão compartilhada, teria mais probabilidade de obter os melhores resultados finais, além de relações mais duradouras e profícuas entre os dois tipos de organização.

Nesse sentido, analisou-se, primeiramente, a figura do designer como agentemeio, integrador do processo de design à luz de Manzini (2011) e Lockwood (2010). A seguir, foram aplicadas as lentes de Mauri (1996) e Watt et al. (2000) para enxergar a relação cliente-consultoria como um projeto coletivo. Por fim, explorou-se a relação cliente-designer conectada ao design discourse de Verganti (2012).

\subsubsection{Designer: facilitador, provocador e integrador}

Ao refletir sobre o design para serviços, Manzini (2011) aborda situações em que as fronteiras entre cliente e fornecedor são pouco definidas. Os atores seriam coprodutores, colaborando com qualidade relacional e eficiência para alcançar um resultado relevante para todos. Nessa visão, o papel do designer se deslocaria tanto do criativo isolado quanto do executor técnico em direção a uma posição de dupla função: facilitação, suscitando conversações sobre o que fazer; e provocação consciente, propondo ideias, discussões e ampliando as visões do grupo de atores. Esse posicionamento implicaria em uma modificação na forma com que o designer se enxerga dentro do processo. A postura do designer como criador e guardião de conhecimentos sobre o artificial deveria ser transformada em uma abordagem mais integradora, de um facilitador especialista que provocasse a colaboração.

A visão de Manzini (2011) é articulável com a de Lockwood (2010), em que o designer muda sua atuação de um contexto de resolução de problemas simples, unidisciplinares, para o trabalho colaborativo em times multidisciplinares. Seu foco transcenderia o artefato, em direção ao processo: "não é o que o design é o que importa, mas o que o design faz" (LOCKWOOD, 2010, p.82, tradução nossa). Ao citar Tim Brown acerca do perfil da personalidade do design thinker, Lockwood (2010) complementa a visão sobre as novas habilidades do designer: empatia, pensamento integrativo, otimismo, experimentação e colaboração - os mesmos atributos, coincidentemente, de uma organização orientada pelo design, o que parece confirmar a forte associação entre a postura do designer e sua vocação dentro do sistema organizacional. 


\subsubsection{Designer e cliente como coletivos que projetam}

A contribuição de Mauri (1996) traz novas luzes à relação cliente-fornecedor do design, não enquanto polos opostos, mas como partes de um coletivo que projeta. Segundo o autor, há uma espécie de "sujeito transpessoal", que não se resumiria a uma soma das individualidades, mas à produção de uma nova forma de inteligência. Mauri (1996) propõe a abertura do sujeito à alteridade como condição essencial para que o projeto em coletividade aconteça em uma relação de respeito, oposta à pretensão de controle ou supremacia. Esse modelo, se transposto para a realidade cliente-consultoria de design, implicaria tanto em um pacto de não-agressão quanto a um convite ao desenvolvimento da empatia. Watt et al. (2000) também propõem a abertura através do rompimento de estruturas, estilos de gerenciamento e culturas tradicionais e rígidos, ressaltando a flexibilidade de modelos e a aceitação de riscos.

Em vez de dois polos opostos, a representação geométrica da proposta de Mauri (1996) seria um círculo em eterno movimento, promotor da simultaneidade e da reciprocidade de relações. Os atores permaneceriam receptivos, expressivos e conceptivos, suspendendo julgamentos e abrindo espaço para dúvidas e perguntas, em detrimento de respostas e confirmações. A gestão de conflitos valorizaria o diferente, explorando a divergência para criação de valor competitivo (MAURI, 1996; WATT et al., 2000). O papel do designer, nesse contexto, seria o de catalisador e organizador do projeto, aliando intuição, percepção, capacidade de escuta e abstração a favor da interlocução estratégica com os tomadores de decisão (WATT et al., 2000).

Meroni e Sangiorgi (2011) vêem essa interação como um caminho comum para dois interlocutores em direção a um estado compartilhado de conhecimento sobre um certo tópico ou problema. Esse diálogo estratégico seria indissociável do projeto e, dentro do contexto de serviços de design, poderia ser exemplificado pelo contrabriefing, o codesign e as visões compartilhadas.

\subsubsection{O design discourse e as redes de projeto}

Verganti (2012) propõe um modelo de pesquisa em rede, expandido para fora das fronteiras da empresa e envolvendo, além de sua equipe interna, usuários e intérpretes do design discourse, rede composta por empresas de outras áreas que buscam os mesmos públicos, fornecedores, pesquisadores, designers e artistas - um círculo de atores em diálogo contínuo, testando suas ideias e compartilhando opiniões. A capacidade-chave de uma empresa, ao adotar o modelo de inovação orientada pelo design, seria de acessar e compartilhar conhecimento com o design discourse, além de identificar os intérpretes-chave, atraí-los e desenvolver com eles uma relação privilegiada (VERGANTI, 2008).

O que Verganti (2008) argumenta pode ser de grande utilidade na reflexão sobre modelos de relacionamento entre empresas e consultorias, pois propõe a saída de um modelo de concentração para um de atribuição e distribuição de controle. Enquanto na relação entre organização e designer a primeira tem o monopólio da autoridade, na visão de Verganti (2012) o intérprete (que poderia ser o designer) seria a autoridade, por estar imerso no contexto social de interesse da empresa para seus projetos. A autoridade (ou credibilidade) do intérprete derivaria de sua capacidade de compreender e influenciar o modo como pessoas dão significados às coisas.

A partir dessa análise, é possível enxergar o relacionamento entre organizações e consultorias de forma articulada, em rede, e não mais polar. O designer poderia ser 
abordado como um dos intérpretes dessa rede, o que implicaria uma mudança estratégica em seu papel e o estabelecimento de relações mais horizontais e distribuídas de autoridade e autoria. A capacidade da organização em se relacionar com o design discourse e, dessa relação, tirar o maior proveito estratégico, seria criadora de vantagem competitiva para a empresa. Essa relação seria tão melhor, de acordo com Verganti (2012), quanto mais participação e interpretação ativa a empresa empreendesse, construindo sua própria visão (em oposição ao modelo passivo, já discutido neste artigo, em que a empresa delega a ação ao consultor).

Duas citações trazidas por Verganti, em momentos distintos, ilustram a responsabilidade de uma organização em se relacionar proativamente com consultorias de design. Na primeira, Alessandro Mendini avalia a fabricante Alessi e seu relacionamento com os intérpretes: "Alessi não nos faz sentir como se trabalhássemos para Alessi. Ao contrário, nós sentimos como se Alessi estivesse trabalhando para nós" (MOON et al, 2004, apud VERGANTI, 2008, p. 451). Na segunda, Eugenio Perazza, fundador da Magis, afirma que "nenhum designer de destaque colaboraria com uma empresa que não soubesse para onde ir" (CASTELLI et al, 2007, apud VERGANTI, 2012, p. 203). Essas falas revelam uma versão interpretada e, quiçá, invertida da polaridade de autoridade. Ao proverem aos intérpretes toda a base para experimentação, os gestores de Alessi e Magis tanto reforçam sua direção criativa quanto se abrem a influências externas inovadoras, participando do design discourse, propondo concepções e recursos para tornarem-se mais atraentes aos intérpretes.

Verganti (2008) também posiciona o designer como gatekeeper, facilitador do acesso da organização ao design discourse e ponte entre diferentes contextos e indústrias, facilitando a polinização cruzada de referências, linguagens, tecnologia e conhecimento. No contexto de estudo deste artigo, pode-se enxergar o designer no papel de gatekeeper tanto enquanto intérprete quanto funcionário da organização.

Embora existam diversas referências sobre a desejabilidade de relações perenes entre as organizações, Verganti (2012) aborda com naturalidade a finitude da relação da organização com os intérpretes, tanto por desgaste natural do ciclo colaborativo, por mudança no contexto ao qual ele está vinculado ou por mudança de momento profissional do intérprete. Essa reflexão traz uma ótica para o fim da relação entre empresas e consultorias que não a do atrito na relação. A necessidade de renovação da rede de intérpretes seria inerente ao modelo de colaboração interorganizacional. Algumas empresas, cientes dessa perecibilidade da colaboração criativa, optariam por uma estratégia que combinasse um núcleo de designers internos articulados a colaboradores-satélite efêmeros, que explorariam conexões em novos universos. Dentro da realidade de clientes e consultorias de design, essa visão implicaria na reorganização da consultoria para formatos de trabalho mais efêmeros, assim como a atualização periódica de sua própria equipe.

\section{CONSIDERAÇÕES FINAIS}

A partir dos referenciais estudados, tornou-se possível antever possíveis caminhos pelos quais o design estratégico poderia refletir e contribuir para a remodelação da relação entre organizações e seus fornecedores de design.

Ao serem reconhecidos os polos de poder de autoridade e autoria, e articulados aos referenciais do design estratégico que poderiam contribuir para sua atenuação, pôde-se chegar à conclusão de que há elementos consistentes para uma 
discussão sobre as relações de trabalho entre clientes e fornecedores nos vários domínios do design. Os modelos colaborativos, o diálogo com o design discourse e a visão do designer como mediador poderiam contribuir para a melhoria das relações interorganizacionais ou, pelo menos, para uma visão mais consciente do processo, de suas limitações e da relevância de posições culturalmente cristalizadas nos papéis corporativos desempenhados pelos autores.

Contudo, é provável que a decisão sobre o avanço dos modelos acima citados dependa de decisões autônomas dos atores envolvidos, intrinsecamente ligadas à sua consciência profissional e motivações pessoais. Estariam designers dispostos a abrir mão da exclusividade da autoria dos projetos? Da mesma forma, as empresas contratantes aceitariam uma relação horizontal com seus fornecedores, compartilhando informações e decisões estratégicas? A resposta para essas questões, a princípio, passaria por uma reflexão sobre o que é mais relevante dentro de um contexto empresarial: a consecução dos objetivos de negócio da empresa ou o reforço a crenças e visões de mundo individuais dos atores.

Futuras pesquisas poderão estudar, com maior profundidade, os motivos de estabelecimento e rompimento de relações dentro de diferentes domínios do design, identificando tanto o potencial de longevidade de relações dentro de cada domínio quanto as formas pelas quais as organizações envolvidas poderiam remodelar suas visões, modelos mentais e processos.

\section{REFERÊNCIAS}

BAGDONAITE, Zivile. The Design-Business Conversation. Dissertação (mestrado), Copenhagen Business School, 2015.

BEST, Kathryn. Fundamentos de Gestão do Design. Porto Alegre: Bookman, 2012.

BRUCE, Margaret; DOCHERTY, Catherine. It's all in a relationship: a comparative study of client-design consultant relationships. Design Studies, v. 14, n. 4, p. 402-422, 1993.

BRUCE, Margaret; MORRIS, Barny. Managing external design professionals in the product development process. Technovation, v. 14, n. 9, p. 585-599, 1994.

CASTELLI, Giulio; ANTONELLI, Paola; PICCHI, Francesca (Ed.). La fabbrica del design: conversazioni con i protagonisti del design italiano. Skira, 2007.

JEVNAKER, Birgit H.; BRUCE, Margaret. Design alliances: The hidden assets in management of strategic innovation. The Design Journal, v. 1, n. 1, p. 24-40, 1998.

LEAKE, Tim. The Naked Truth. 2014. Disponível na internet por http em: <http://getnakedatcannes.com>. Acesso em 23 abr. 2016

LEONARD-BARTON, Dorothy. Wellsprings of knowledge: Building and sustaining the sources of innovation. University of Illinois at Urbana-Champaign's Academy for Entrepreneurial Leadership Historical Research Reference in Entrepreneurship, 1995.

LOCKWOOD, Thomas. Transition: becoming a design-minded organization. In: Design Thinking: Integrating Innovation, Customer Experience, and Brand Value. New York: Allworth Press, p.81-95, 2010. 
MANZINI, Ezio. Introduction. In: Design for services. Gower Publishing, p.1-6; 201-209, 2011.

MAURI, Francesco. Progettare progettando strategia. Milano: Masson S.p.A, 1996.

MERONI, Anna; SANGIORGI, Daniela. Design for services. Gower Publishing, p.1-6; 201209, 2011.

MEYER, Guilherme. Conflito, negociação e transformação: o designer e o processo de desenvolvimento de produto. 2010. Tese (doutorado) - PUC-Rio.

MOON, Youngme; DESSAIN, Vincent; SJÖMAN, Anders. Alessi: Evolution of an Italian Design Factory (A). Harvard Business School Case Study, 2004.

MOZOTA, Brigite Borja de et. al. Gestão do Design. Porto Alegre: Bookman, 2011.

SILVA, Lina Maria Moreira Garay da; TARSITANO, Paulo Rogério. A relação agênciacliente: a ética na ótica do atendimento de publicidade. Anais do XXIX Congresso Brasileiro de Ciências da Comunicação, 2006.

VERGANTI, Roberto. Design, meanings and radical innovation: A metamodel and a research agenda. Journal of Product Innovation Management, v.25, n.5, p 436-456, 2008.

VERGANTI, Roberto. Design-driven innovation: mudar as regras da competição: a inovação radical do significado de produtos. São Paulo: Canal Certo, 2012.

WATT, Cameron; RUSSELL, Ken; HASLUM, Mary. Stronger relationships make stronger design solutions. Design Management Journal (Former Series), v. 11, n. 2, p. 46-52, 2000. 